\title{
CME (Continuing Medical Education) CMS (Combined Morning Session) January-June 2020
}

\begin{tabular}{|l|l|l|}
\hline Date & Topic & Speaker \\
\hline 09.01.2020 & Possibility of Chronic Pesticide Poisoning & Professor Dr. M. Jalal Uddin \\
\hline 28.01 .2020 & Panic Disorder & Dr. Mohammad Mostafa \\
\hline 10.02 .2020 & Benign Enlargement of Prostate & Dr. Utpak Kumar Das \\
\hline 20.02 .2020 & Environmental Dermatoses in Climate Changes & Dr. Shamsun Nahar Bintha Mannan \\
\hline 11.03 .2020 & Kidney for Everyone Everywhere & Professor Dr. M. A. Kashem \\
\hline
\end{tabular}

\section{List of Reviewers and Editors}

Reviewers ensure the rigorous standards of the scientific process by taking part in the peer-review system, uphold the integrity of the journal by identifying invalid research and helping to maintain the quality of the journal. We express our deep gratitude to them for their pain taking and sincere effort.

\begin{tabular}{|l|l|}
\hline Name & Discipline \\
\hline Professor A S M Mostaque Ahmed & Pathology \\
\hline Professor Alak Kanti Biswas & Orthopedic Surgery \\
\hline Professor M. Jalal Uddin & Community Medicine \\
\hline Professor Nahid Sultana & Microbiology \\
\hline Professor Abdul Qayum Chowdhury & Otorhinolaryngology \\
\hline Professor Sanjoy Kanti Biswas & Microbiology \\
\hline Professor Babul Osman Chowdhury & Pathology \\
\hline Professor Razia Sultana & Pathology \\
\hline Dr. Mozammel Hoque Sharife & Ophthalmology \\
\hline Dr. Dipika Dey & Neonatology \\
\hline Dr. Rajat Sankar Roy Biswas & Medicine \\
\hline Dr.Farahnaz Mabud & Obstetrics \& Gynaecology \\
\hline Dr. Muhammad Abu Bakar & Endocrinology \\
\hline
\end{tabular}

[This list is not according to seniority] 